\title{
Neurological complications of severe illness and prolonged mechanical ventilation
}

\author{
C M Wiles \\ Department of Medicine (Neurology), University of Wales College of Medicine, \\ Cardiff, UK
}

Introductory article

\section{The role of polyneuropathy in motor convalescence after prolonged mechanical ventilation}

Frans S S Leijten, Joukje E Harinck-de Weerd, Dick C J Poortvliet, AI W de Weerd

Objective. To test the hypothesis that prolonged motor recovery after long-term ventilation may be due to polyneuropathy and can be foreseen at an early stage by electromyography (EMG). Design. Cohort study with an entry period of 18 months. Polyneuropathy was identified by EMG studies in the intensive care unit (ICU). During a 1-year follow-up, amount of time was recorded to reach a rehabilitation end point. Setting. The general ICU of a community hospital. Patients. Fifty patients younger than 75 years who were receiving mechanical ventilation for more than 7 days. Main outcome measures. $A$ rehabilitation end point was defined as return of normal muscle strength and ability to walk $50 \mathrm{~m}$ independently. Results. In 29 of 50 patients, an EMG diagnosis of polyneuropathy was made in the ICU. Patients with polyneuropathy had a higher mortality in the ICU (14 vs 4; $P=0.03)$, probably related to multiple organ failure (22 vs $11 ; P=0.08)$ or aminoglycoside treatment of suspected gram-negative sepsis (17 vs 4; $P=0.05$ ). Rehabilitation was more prolonged in 12 patients with polyneuropathy than in 12 without polyneuropathy $(P=0.001)$. Of nine patients with delays beyond 4 weeks, eight had polyneuropathy, five of whom had persistent motor handicap after 1 year. In particular, axonal polyneuropathy with conduction slowing on EMG indicated a poor prognosis. Conclusions. Polyneuropathy in the critically ill is related to multiple organ failure and gram-negative sepsis, is associated with higher mortality, and causes important rehabilitation problems. EMG recordings in the ICU can identify patients at risk. (JAMA 1995;274:1221-5)

With a few recognised exceptions, adult neuromuscular disorders rarely present with respiratory impairment. However, in the ventilated and often sedated patient in the intensive care unit (ICU) the repertoire of physical movement and sensation is restricted and weakness of the respiratory muscles (manifest as difficulty in weaning) may be the first and most immediate evidence that there is a neuromuscular disorder.

The ability to sustain independent ventilation depends on achieving a balance between the work required for effective ventilation and the capacity of the respiratory muscles. On one side of this equation various factors may combine to increase the work of breathing including impaired cardiac and pulmonary function, supine posture, upper airway obstruction (including the added resistance of any external ventilatory circuit), and impaired control of pharyngeal contents leading to aspiration. On the other side the neuromuscular drive to breathe can potentially be impaired at any level; specifically, abnormal control of, or reduced drive to, the respiratory, upper airway and swallowing muscles may contribute directly or indirectly to a failure of independent breathing, and, in addition, the muscles themselves may become weakened or fatiguable. Assessment of the integrity of drive to the respiratory muscles by measuring force output, contractility and susceptibility to fatigue has become increasingly developed in recent years. ${ }^{12}$ However, most of these measurements are dependent on activation of the final common pathway (lower motor neurone) by voluntary effort or electrical stimulation. Once the central nervous system is impaired by drugs, disease, or injury, the dissection of abnormal bulborespiratory function into its component parts becomes more problematic.

Conventionally, breathing, upper airway control, and swallowing can be maintained at a brainstem level of integration and, for breathing at least, there are separate voluntary and automatic pathways of activation to the relevant anterior horn cells; reflex cough and emotion may involve yet other pathways. ${ }^{3-5}$ Differential sus- 
ceptibilities of these activation pathways to the effects of depressed consciousness, illness, injury, and drugs are important in the various clinical features of neurogenically impaired breathing. In addition, a wide range of neurological deficits may adversely affect upper airway control and breathing.

Why then may a patient fail to breathe adequately after a period in the ICU? This question is always predicated on the fact that medication which depresses the ability to breathe has cleared, that the airway is patent, and that the lungs are neither excessively obstructed nor filled with fluid. Experienced physicians will, however, be familiar with reassurances about the "short actions" of various relaxant and depressant agents which have turned out to be optimistic or superseded by new information, particularly about metabolites in the context of multiple organ failure, notably renal and hepatic impairment. This problem is especially relevant when an agent has been administered for many days or weeks. Various publications attest to the ongoing importance of this issue - for example, after vecuronium, ${ }^{6}$ pancuronium, ${ }^{78}$ opiate metabolites, ${ }^{9}$ and midazolam. ${ }^{10}$ Prolonged action of depressant drugs on central nervous system function can be suspected from clinical examination (for example, pupil size with opiates), from the EEG, from detailed inspection of the patients' drug charts in the context of their metabolic state, and can sometimes be confirmed by measurement of blood levels of the drug (or metabolites) or by the use of specific agents to reverse function (for example, naloxone, flumazenil). If there is doubt about peripheral nerve, neuromuscular junction, or muscle function, it is essential to confirm the presence of muscle contraction in cranial nerve territory and limbs. Conventionally this is done by observing a motor response to command or painful stimulation, to tendon reflex stimulation, or by the use of a peripheral nerve stimulator. Complete absence of motor responses should trigger a more formal neurophysiological evaluation with nerve conduction and repetitive stimulation studies. A high index of suspicion about the role of medication in prolonged respiratory depression is probably warranted.

\section{Neurological causes of failure to wean}

Failure to breathe after artificial ventilation following surgery, trauma, or a severe illness can be classified in various ways from a neurological standpoint; pragmatically, several different clinical situations are recognised. The patient may have a diagnosed pre-existing neurological disability such as prior poliomyelitis, genetic neuropathy, or muscular dystrophy affecting swallowing, breathing capacity, or airway control which has complicated the course of anaesthesia ${ }^{11}$ or some illness. Anticipation of difficulties is the key to prevention in such individuals.

An unanticipated neurological event may have complicated a non-neurological injury, illness, or medication. Suspicion of, for example, cardiogenic embolism following heart surgery or hypoxic ischaemic cerebral injury after cardiac arrest is usually aroused because of other features - notably, failure to regain normal consciousness. Whilst acute stroke may certainly produce measurable effects on contralateral respiratory muscle function, cerebrovascular events rarely cause symptomatic respiratory muscle weakness or failure to breathe unless secondary to major brainstem distortion or compression as may follow a cerebellar haematoma or uncal herniation secondary to extensive cerebral hemisphere swelling. Caution is therefore needed when attributing failure to breathe to a "brainstem stroke". In the context of sepsis and multiple organ failure, many factors can contribute to an encephalopathic or peripheral neuromuscular state ${ }^{12}$ which may impede respiratory, airway, or swallowing function (see below). Intrathoracic disease or its treatment may be unexpectedly complicated by anterior spinal artery occlusion or phrenic nerve injury with consequent respiratory muscle weakness. Rarely, Guillain-Barré syndrome complicates unrelated illness or surgery (but see also below).

There may be a primary neurological cause for ICU admission such as head injury, subarachnoid haemorrhage, or meningitis with consequent specific neurological deficits. Again, failure to breathe is usually associated with rostrocaudal depression of brainstem function in the context of bihemispheric brain swelling and dysfunction - depressed level of consciousness is the major feature. A pontine, medullary, or high spinal insult occasionally results in respiratory failure and general paralysis with clear preservation of consciousness basilar artery occlusion with ventral pontine infarction is a typical example. In the general ICU setting such a "locked in" syndrome may be missed unless the patient is personally questioned appropriately and examined for preserved voluntary vertical eye movements after withdrawal of sedation and relaxants. Such patients may have impaired voluntary control of respiratory muscles and may not cough, suspend respiration, or take a deep breath to command. When there are focal neurological signs indicative of a medullary lesion (for example, IX-XII cranial nerves) or a high anterior spinal lesion, disorders of the automatic control of breathing may be anticipated and assessment of breathing during sleep (however normal it appears whilst awake) should be carried out since the ability to undertake voluntary tests of breathing may well be unremarkable if the pyramidal pathways are intact.

It is in patients with peripheral neuromuscular disease that failure to wean from a ventilator should be most readily anticipated. Whilst this is most commonly the result of the primary condition - for example, myasthenia gravis - a secondary neurological insult such as Guillain-Barré syndrome, critical illness neuropathy (see below), porphyria, or unexpected drug-disease interactions may occasionally play a part. Recently, for example, severe muscle weakness following high dosage steroids in the context of either pharmacological neuromuscular blockade or myasthenia gravis and associated with loss of myosin thick filaments has been described. ${ }^{1314}$

Finally, there is a small group of patients who arrive on the ICU as a result of failure to breathe unexpectedly after an anaesthetic or who present with either severe respiratory failure or apnoea without evident cause. Examples are the patient who fails to breathe after cataract surgery and is found to have myotonic dystrophy, or the patient with unremarked respiratory muscle weakness who has a trivial complaint of orthopnoea preoperatively but fails to breathe following laparotomy and is found to have motor neurone disease. ${ }^{15}$ The practical context is that of a patient who is clearly fully conscious, sedation and relaxant free who fails to breathe but who may not have major focal neurological signs. A neurological opinion in such circumstances may be useful since positive diagnostic features of muscle disease or motor neurone disease or a hind brain malformation (Chiari malformation) may be subtle or trivial. 


\begin{tabular}{|c|c|c|}
\hline Complication & Neurological consequence & Functional consequence \\
\hline Hypotension & $\begin{array}{l}\text { Hypoxic-ischaemic cerebral or borderzone } \\
\text { infarct } \\
\text { Anterior spinal artery syndrome }\end{array}$ & $\begin{array}{l}\text { Depressed consciousness } \\
\text { Faciobrachial weakness } \\
\text { Cortical visual loss } \\
\text { Weak arms, legs, respiratory muscles }\end{array}$ \\
\hline $\begin{array}{l}\text { Cardiac complications } \\
\text { (low output, arrhythmia, endocarditis and } \\
\text { embolism) }\end{array}$ & $\begin{array}{l}\text { As for hypotension } \\
\text { Infarct or haemorrhagic infarct }\end{array}$ & $\begin{array}{l}\text { Depressed consciousness } \\
\text { Focal signs }\end{array}$ \\
\hline $\begin{array}{l}\text { Other organ failure: } \\
\text { Liver } \\
\text { Kidney } \\
\text { Pancreas }\end{array}$ & Encephalopathy & $\begin{array}{l}\text { Depressed consciousness } \\
\text { Seizures, myoclonus }\end{array}$ \\
\hline $\begin{array}{l}\text { Metabolic events: } \\
\text { Nutritional failure }\end{array}$ & $\begin{array}{l}\text { Neuromyopathy } \\
\text { Specific deficiency (eg vitamin } B_{\mathfrak{l}} \text { ) } \\
\text { Protein calorie deficit }\end{array}$ & Wasting and weakness \\
\hline Hyponatraemia & $\begin{array}{l}\text { Seizures, confusion, focal signs, central } \\
\text { pontine myelinolysis }\end{array}$ & \multirow{2}{*}{$\begin{array}{l}\text { Depressed consciousness } \\
\text { Focal signs, weakness } \\
\text { Muscle weakness } \\
\text { Tetany, seizures }\end{array}$} \\
\hline $\begin{array}{l}\text { Hypokalaemia } \\
\text { Hypocalcaemia/hypomagnesaemia }\end{array}$ & $\begin{array}{l}\text { Myopathy } \\
\text { Impaired synaptic, neuromuscular junction } \\
\text { function }\end{array}$ & \\
\hline $\begin{array}{l}\text { Hypophosphataemia } \\
\text { Hypoglycaemia }\end{array}$ & $\begin{array}{l}\text { Energy depletion } \\
\text { Encephalopathy }\end{array}$ & \multirow{2}{*}{$\begin{array}{l}\text { Muscle weakness } \\
\text { Depressed consciousness } \\
\text { Seizures } \\
\text { Depressed consciousness } \\
\text { Focal eye signs, weakness, ataxia }\end{array}$} \\
\hline Thiamine deficiency & Neuropathy, Wernicke's encephalopathy & \\
\hline \multirow{3}{*}{$\begin{array}{l}\text { Medication } \\
\text { Sedative drugs } \\
\text { Antiemetics/tranquillisers } \\
\text { Muscle relaxants }\end{array}$} & $\begin{array}{l}\text { Encephalopathy } \\
\text { Extrapyramidal syndromes including }\end{array}$ & \multirow{4}{*}{$\begin{array}{l}\text { Depressed consciousness } \\
\text { Impaired bulborespiratory function } \\
\text { Rigidity, fever (raised creatine kinase) } \\
\text { Prolonged weakness } \\
\text { Muscle rigidity, fever, raised creatine kinase } \\
\text { Weakness and autonomic instability } \\
\text { Weakness }\end{array}$} \\
\hline & $\begin{array}{l}\text { neuroleptic malignant syndrome } \\
\text { Neuromuscular blockade }\end{array}$ & \\
\hline & $\begin{array}{l}\text { Malignant hyperpyrexia } \\
\text { Porphyric neuropathy } \\
\text { Myopathy (type II fibre and myosin filament } \\
\text { loss) }\end{array}$ & \\
\hline $\begin{array}{l}\text { Aminoglycosides } \\
\text { Cyclosporin }\end{array}$ & $\begin{array}{l}\text { Vestibular and ototoxicity } \\
\text { Encephalopathy }\end{array}$ & \\
\hline \multirow{3}{*}{$\begin{array}{l}\text { Other: } \\
\text { Fever } \\
\text { Pressure/stretch } \\
\text { Instrumentation e.g. jugular, subclavian } \\
\text { lines } \\
\text { "Septic" encephalopathy } \\
\text { Critical illness neuropathy }\end{array}$} & $\begin{array}{l}\text { ?Neuropathy } \\
\text { Mononeuropathy (ulnar, common peroneal) } \\
\text { Brachial olexus neuritis }\end{array}$ & \\
\hline & $\begin{array}{l}\text { Phrenic nerve lesions } \\
\text { Brachial plexus neuritis } \\
\text { Depressed conscioussess, tremor, myoclonus } \\
\text { Rigidity (see ref 12) }\end{array}$ & \\
\hline & See text & See text \\
\hline
\end{tabular}

\section{Neuromuscular complications of severe illness (table)}

Ill patients without known neuromuscular disease are prone to several events which may be associated with neurological complications. The most common, which are associated with failure to regain normal consciousness with or without focal signs, are the result of prolonged hypotension or relative hypotension in either a previously hypertensive patient or one who has flow limiting extracranial or intracranial vascular stenoses. Elderly patients who have undergone surgery requiring cardiac bypass are clearly susceptible; other relevant postoperative complications are interference with the spinal cord blood supply by either the primary pathology - for example, aortic dissection - or thoracotomy per se. Whilst bilateral face and arm weakness with cortical blindness (often mistaken for "confusion" or "functional" disturbance) may be features of borderzone infarction following prolonged hypotension, weak legs with preserved posterior column function and a variable pain/temperature sensory level may be features of anterior spinal artery occlusion which, depending on the level, may affect inspiratory and/or expiratory function. Metabolic disturbances predominantly affect higher cerebral function first before causing focal signs, although muscle weakness associated with hypokalaemia and hypophosphataemia are exceptions and certainly may contribute to difficulty in weaning. Vitamin sup- plementation (especially thiamine) is occasionally inadequate in patients who are subclinically deficient for example, cachectic or alcoholic - and who are enterally or parenterally fed high carbohydrate loads in the context of a serious intercurrent illness.

As noted above, sedative and relaxant drugs may persist unexpectedly causing central or peripheral neuromuscular side effects. Many antiemetics can cause clinically significant extrapyramidal syndromes and the dopamine blocking action of these, and neuroleptic drugs in general, can have important adverse effects on bulbar function, notably on swallowing. Omission of usual antiParkinsonian medication in the context of a general medical illness or surgical operation may be associated with severe bradykinesia and rigidity and consequent impairment of bulbar and respiratory function. Occasionally these extrapyramidal syndromes are associated with extreme rigidity, fever, and muscle breakdown with a raised creatine kinase level (neuroleptic malignant syndrome). The thin, cachectic, or diabetic patient may be particularly susceptible to pressure palsies (even occasionally sciatic) and the phrenic nerves or brachial plexuses may be traumatised by injury or disease and by surgical procedures - for example, median sternotomy or neck instrumentation. Genetic susceptibility to drugs as in malignant hyperpyrexia or porphyria is rare but clinically potentially devastating when it occurs. 


\section{Critical illness neuropathy}

Thus, it is against a background of many possibilities both iatrogenic and caused by injury or disease - that a particular group of patients becomes evident in whom life-threatening illness is followed by prolonged weakness on recovery. This group manifests itself initially in delayed weaning from ventilation. Such patients are generally characterised by periods of care in the ICU of a month or more, having been admitted for a wide range of causes but often culminating in sepsis and multiple organ failure. ${ }^{1617}$ Some patients may die in the ICU and evaluation of others can be difficult because of "septic encephalopathy" or sedation. Nevertheless, available clinical features often include symmetrical proximal and distal flaccid weakness with depressed or absent tendon reflexes and, when assessable, distal sensory impairment. Despite improvement from the underlying illness, such patients often fail to breathe spontaneously and sometimes have obvious features of diaphragmatic weakness. The creatine kinase level is normal.

Neurophysiological studies indicate that the patterns of focal or generalised slowing of conduction (or conduction block) associated with local pressure injury or conditions such as Guillain-Barré syndrome are absent - indeed, motor latencies (distal) and F wave latencies (proximal) are generally normal. The sensory nerve action potentials may be reduced in amplitude as are the amplitudes of the compound muscle action potentials in response to supramaximal stimulation, both findings being consistent with loss of functioning axons rather than a process primarily affecting the myelin sheath. In keeping with this axonal injury, electromyography of muscles shows fibrillation potentials at rest and other features of denervation; the electromyographic features are evident not only in limb muscles but also in the intercostal muscles and the diaphragm. ${ }^{1819}$ Whilst it is recognised that the Guillain-Barre syndrome occasionally occurs in an acute axonal form with early denervation changes in muscles rather than motor conduction block or slowing, ${ }^{20}$ by and large the features of critical illness neuropathy differ and examination of cerebrospinal fluid is usually normal. In patients who die, morphological examination of nerves confirms extensive motor and sensory axonal loss with some chromatolysis of anterior horn cells and loss of dorsal root ganglion cells; as anticipated, there are changes of acute and chronic denervation in muscles (including respiratory muscles) and inflammation is absent. ${ }^{16}$

Since the recognition of this condition, a number of prospective studies have suggested that "critical illness neuropathy" is not uncommon in patients who require prolonged ventilation, often in the setting of septic complications. ${ }^{172122}$ Recognition in the early stages is difficult because physical examination of the nervous system is, at best, limited and nerve conduction and EMG studies are necessary for clear documentation.

Attempts have been made to analyse recognised precipitants for neuropathy in what is always a complex clinical situation but no single nutritional factor, pattern of organ failure, group of medications, or clinical event other than sepsis appears to provide an adequate explanation. Indeed, not all cases are associated with sepsis - for example, Wilmshurst et $a l^{23}$ recently reported a patient with high fever associated with a new diagnosis of phaeochromocytoma following hip surgery which was associated with fatal neuropathy. Myopathy associated with prolonged inactivity, cachexia, high energy phosphate depletion, or acute muscle fibre necrosis related to non-depolarizing muscle blockade and steroids may contribute to delayed clinical recovery. ${ }^{24}$ In addition, degradation of muscle protein may be promoted in sepsis by cytokines from leucocytes. ${ }^{2526}$ How frequently both muscle and nerve pathology contribute to the clinical picture is unclear, ${ }^{27}$ but the neurophysiological studies would seem to favour a neural injury in most cases. Increased levels of serum creatine kinase, unless very marked $(10 \times$ normal), may not distinguish nerve from muscle disease in this context.

The recent paper by Leijten et $a l^{22}$ contributes to the discussion about critical illness neuropathy. This group looked prospectively at a group of 72 patients aged $<75$ years who had been receiving mechanical ventilation in a general intensive care unit for more than seven days (a total of 1764 patients were admitted to the ICU of whom 368 were ventilated for more than 24 hours in the same period). Diagnosis was neurophysiologically based initially with nerve conduction and EMG studies being undertaken at least once in 50 patients and polyneuropathy classified according to strict criteria; there is, however, some lack of clarity about the precise timing of EMG studies. Admission to the ICU in these 50 patients followed acute or complicated elective surgery (heart, chest, abdomen) in 19, primary infection and sepsis in 12, trauma in nine, and cardiac resuscitation, status asthmaticus and intracranial haemorrhage in 10 . Thirty two patients survived the ICU period; these patients were neurologically examined shortly after independence from ventilatory support and subsequently at intervals over the next 12 months. Twenty nine of the 50 patients showed evidence of polyneuropathy, about three quarters of whom had predominantly axonal features; some had, in addition, slowing of conduction (mixed polyneuropathy). Clinical features indicative of muscle disease were not seen on full examination in six patients who could cooperate with voluntary muscle contractions and were examined in the rehabilitation period. The neuropathy and "non-neuropathy" groups were carefully compared for risk factors: differences between the groups appeared few and, in particular, no obvious difference for exposure to vecuronium or midazolam was evident but aminoglycosides were given to $59 \%$ of those with neuropathy compared with $19 \%$ without. Although APACHE II scores at admission were similar, the mortality rate in the ICU was much higher ( 3.5 fold) for patients with neuropathy and this group had a greater tendency to multiorgan failure. Of 24 evaluable patients who survived the ICU period, there was a striking delay in motor recovery; in the 12 with polyneuropathy five had severe deficits after a year (four with mixed axonal neuropathy) compared with none in the non-neuropathy group. There were no major differences in premorbid evidence of neuropathy and sepsis occurred no more frequently in the patients with neuropathy with only about half having septic complications.

This study therefore confirms that neuropathy is frequently associated with prolonged ventilation in the ICU and occurs in a wide range of clinical settings. Clearly more research is required to clarify the underlying cause(s), but awareness of the condition should also promote due care and attention in preventing the avoidable causes of neuropathy (table). It is also clear that neuropathy will be undetected until late in the day unless neurophysiological techniques are utilised to detect it.

However, it is important not to assume that every patient who is slow to breathe spontaneously after prolonged ventilation has "critical illness neuropathy" there are other possibilities. Furthermore, even when 


\section{LEARNING POINTS \\ In the patient in the intensive care unit who has had prolonged ventilation and there is difficulty in weaning:}

* Consider the effects of medication.

* Utilise peripheral neurophysiological assessment.

* Obtain a neurological opinion.

* Critical illness neuropathy is a potentially important cause.

diagnostically likely, it is currently unclear how such findings should impinge on the decision making processes in the critically ill patient. Caution is warranted in attributing a poor prognostic outcome on the basis of neuropathy as an independent risk factor until considerably wider experience and more prospective research is available.

I am grateful to Dr M Smithies (Director of Intensive Care, University Hospital of Wales) for helpful comments on the manuscript.

1 Koulouris N, Mulvey DA, Laroche CM, Sawicka EH, Green M, Moxham J. The measurement of inspiratory muscle strength by sniff esophageal, nasopharyngeal, and mouth pressures. Am Rev Respir Dis 1989;139:641-6.

2 Moxham J. Tests of respiratory muscle function. Probl Respir Care 1990; 3:312-28.

3 Nathan PW. The descending respiratory pathway in man. 7 Neurol Neurosurg Psychiatry 1963;26:487-99.

4 Newsom Davis J. Autonomous breathing: report of a case. Arch Neurol 1974;30:480-3.

5 Howard RS, Newsom Davis J. The neural control of respiration. In: Crockard HA, Hayward RD, Hoff J, eds. Neurosurgery: the scientific basis of clinical practice. 2nd edn. Oxford: Blackwell Scientific, 1992: 318-33.

6 Segredo V, Caldwell JE, Matthay MA, Sharma ML, Gruenke- LD, Miller RD. Persistent paralysis in critically ill patients after long-term Miller RD. Persistent paralysis in critically ill patients after long-te

7 Gooch JL, Suchyta MR, Balbierz JM, Petajan JH, Clemmer TP. Prolonged paralysis after treatment with neuromuscular blocking drugs. Crit Care Med 1991;19:1125-31.

8 Rossiter A, Souney PF, McGowan S, Carvajal P. Pancuronium-induced prolonged neuromuscular blockade. Crit Care Med 1991;19:1583-7.

9 Osborne R, Joel S, Trew D, Slevin ML. Morphine and metabolite behaviour and different rates of morphine administration: demonstration of the active metabolite morphine-6-glucuronide. Clin Pharm Ther 1990;47:12-9.

10 Bauer TM, Ritz R, Haberthurl C, et al. Prolonged sedation due to accumulation of conjugated metabolites of midazolam. Lancet 1995; 346:145-7.
11 Patrick JA, Meyer-Witting M, Reynolds F, Spencer GT. Peri-operative care in restrictive respiratory disease. Anaesthesia 1990;45:390-5.

12 Bolton CF, Young GB. Neurological complications in critically ill patients. In: Aminoff MJ, ed. Neurology and general medicine. 2nd edn. New York: Churchill Livingstone, 1995:859-78.

13 Hirano M, Ott BR, Raps EC, et al. Acute quadriplegic myopathy: a complication of treatment with steroids, non-depolarizing blocking agents or both. Neurology 1992;42:2082-7.

14 Panegyres PK, Squier M, Mills KR, Newsom-Davis J. Acute myopathy associated with large parenteral dose of corticosteroid in myasthenia gravis. 7 Neurol Neurosurg Psychiatry 1993;56:702-4.

15 Howard RS, Wiles CM, Loh L, Respiratory complications and their management in motor neurone disease. Brain 1989;112:1155-70.

16 Zochodne DW, Bolton CF, Wells GA, et al. Critical illness polyneuropathy: a complication of sepsis and multiple organ failure. Brain 1987:110:819-42.

17 Witt NJ, Zochodne DW, Bolton CF, et al. Peripheral nerve function in sepsis and multiple organ failure. Chest 1991;99:176-84

18 Bolton CF, Gilbert JJ, Hahn AF, Sibbald WJ. Polyneuropathy in critically ill patients. F Neurol Neurosurg Psychiatry 1984;47:1223-31

19 Bolton CF, Laverty DA, Brown JD, Witt NJ, Hahn AF, Sibbald WJ. Critical illness polyneuropathy: electrophysiological studies and differentiation from Guillain-Barré syndrome. 7 Neurol Neurosurg Psychiatry 1986;49:563-73.

20 Feasby TE, Gilbert JJ, Brown WF, et al. An acute axonal form of Guillain-Barré polyneuropathy. Brain 1986;109:1115-26.

21 Spitzer AR, Giancarlo T, Maher L, Awerbuch G, Bowles A. Neuromuscular causes of prolonged ventilator dependency. Muscle Nerve muscular causes

22 Leijten FSS, Harinck-de Weerd JE, Poortvliet DCJ, de Weerd AW. The role of polyneuropathy in motor convalescence after prolonged Thechanical ventilation $7 A M A$ 1995:274:1221-5.

23 Wilmshurst PT, Treacher DT, Lantos PL, Wiles CM. Critical illness polyneuropathy following severe hyperpyrexia. $Q \mathcal{F}$ Med 1995;88 $351-5$

24 Zochodne DW, Ramsay DA, Saly V, Shelley S, Moffatt S. Acute necrotizing myopathy of intensive care: electrophysiological studies. Myopathy in critical illness. Muscle Nerve 1994;17:285-92.

25 Baracos V, Rodemann P, Dinarello CA, Goldberg AL. Stimulation of muscle protein degradation and prostaglandin E2 release by leukocytic pyrogen (interleukin-1). $N$ Engl f Med 1983;308:553-8.

26 Clowes GHA, George BC, Villee CA, Saravis CA. Muscle proteolysis induced by a circulating peptide in patients with sepsis of trauma. $N$ Engl $f$ Med 1983;308:545-52.

27 Latronico N, Fenzi F, Recupero D, et al. Critical illness myopathy and neuropathy. Lancet 1996;347:1579-82. 